Pacific Journal of Mathematics

TRANSFORMATION FORMULAE FOR MULTIPLE SERIES 


\title{
TRANSFORMATION FORMULAE FOR MULTIPLE SERIES
}

\author{
R. Sita RamachandRa Rao and M. V. Subbarao
}

In this paper we prove a general transformation formula for a triple series of complex terms. We deduce a transformation formula for double series and discuss some applications. Furthermore, some reciprocity relations of the following type are obtained: Let $a, b, c$ be reals greater than 1 and

$$
P(a, b, c)=\sum_{r=1}^{\infty} r^{-a} \sum_{k=1}^{r} k^{-b} \sum_{l=1}^{k} l^{-c} .
$$

Then

$$
\begin{aligned}
P(a, b, c)+P(a, c, b)+ & P(b, c, a)+P(b, a, c) \\
& +P(c, a, b)+P(c, b, a) \\
= & \zeta(a) \zeta(b) \zeta(c)+\zeta(a) \zeta(b+c) \\
& +\zeta(b) \zeta(c+a)+\zeta(c) \zeta(a+b)+2 \zeta(a+b+c),
\end{aligned}
$$

where $\zeta$ denotes the Riemann zeta function. In particular, $P(2,2,2)=$ $31 \pi^{6} / 15,120$.

1. Introduction. Since the time of Euler, the evaluation of certain infinite series, in closed form, in terms of the Riemann zeta function and allied functions is familiar. The processes involved, at times, yield recurrence relations among these functions. Results of this kind, dating back to 1743 and due to Euler, can be found in N. Nielsen's book (cf. [6], Erster Teil, Kapitel III). It appears that some recent authors are not aware of these results. For example, in 1953, G. T. Williams (cf. [9], Theorems III and I) proved the following results:

$$
\begin{gathered}
2 \sum_{r=1}^{\infty} \frac{1}{r^{a}} \sum_{k=1}^{r} \frac{1}{k}=(a+2) \zeta(a+1)-\sum_{i=1}^{a-2} \zeta(a-i) \zeta(i+1), \\
\zeta(2) \zeta(2 a-2)+\zeta(4) \zeta(2 a-4)+\cdots+\zeta(2 a-2) \zeta(2) \\
\quad=\left(a+\frac{1}{2}\right) \zeta(2 a),
\end{gathered}
$$

where $a$ is an integer $\geq 2$ and $\zeta$ denotes the Riemann zeta function defined by $\zeta(s)=\sum_{n=1}^{\infty} n^{-s}$ for $s>1$. Williams claims that (1.1) is "apparently entirely new" and that the convolution considered in (1.2) "seems never to have been explicitly formulated before" (see also [3], [4], [2], and [7]). But we note that (1.1) and (1.2) are already deduced in 
Nielsen (cf. [6], p. 47, Eqs. (3) and (4)) in a very elegant way and apparently go back to Euler (see footnotes on p. 47 of Nielsen [6]). Probably Nielsen's techniques were essentially those of Euler!. Nielsen (cf. [6], p. 47) makes use of some reciprocity relations to evaluate certain infinite series and further to deduce various recurrence relations involving the Riemann zera function and allied functions ((1.1) and (1.2) are just typical of these results). A careful examination of Nielsen's proofs shows that they hinge on a certain transformation formula for double series which, however, is not explicitly stated in the book. In $\$ 2$ we prove a transformation formula of a very general nature for triple series, which is believed to be new. In $\S 3$ we deduce a transformation formula for double series, which in turn yields as special cases all the basic reciprocity relations on p. 47 of Nielsen's book [6]. In $\$ 4$ we further illustrate our transformation formula for triple series by deducing various reciprocity relations and also evaluate some infinite series as special cases. Typical of our results is the following:

$$
\sum_{r=1}^{\infty} \frac{1}{r^{2}} \sum_{k=1}^{r} \frac{1}{k^{2}} \sum_{l=1}^{k} \frac{1}{l^{2}}=\frac{31}{15,120} \pi^{6} .
$$

2. Transformation formula for triple series. Let $\sum_{r, k, l=1}^{\infty} f(r, k, l)$ be an absolutely convergent triple series with complex terms. Then the following transformation formula holds.

THEOREM 2.1. We have

$$
\begin{aligned}
\sum_{r, k, l=1}^{\infty} f(r, k, l) & \\
= & \sum_{r=1}^{\infty} \sum_{k=1}^{r} \sum_{l=1}^{k}\{f(r, k, l)+f(r, l, k)+f(k, l, r) \\
& \quad+f(k, r, l)+f(l, r, k)=f(l, k, r)\} \\
& -\sum_{r=1}^{\infty} \sum_{k=1}^{r}\{f(r, k, k)+f(r, k, r)+f(k, r, k)+f(k, r, r)\} \\
& -\sum_{r=1}^{\infty} \sum_{k=1}^{\infty} f(r, r, k) .
\end{aligned}
$$

Proof. The absolute convergence of the triple series $\sum_{r, k, l=1}^{\infty} f(r, k, l)$ justifies the rearrangements that we perform in the sequel. We write

$$
\begin{aligned}
\sum_{r, k, l=1}^{\infty} f(r, k, l) & =\sum_{r=1}^{\infty} \sum_{k \leq r} \sum_{l=1}^{\infty} f(r, k, l)+\sum_{r=1}^{\infty} \sum_{k>r} \sum_{l=1}^{\infty} f(r, k, l) \\
& =\sum_{1}+\sum_{2}
\end{aligned}
$$


and

$$
\begin{aligned}
\sum 1 & =\sum_{r=1}^{\infty} \sum_{k \leq r} \sum_{l \leq k} f(r, k, l)+\sum_{r=1}^{\infty} \sum_{k \leq r} \sum_{l>k} f(r, k, l) \\
& =\sum_{1}^{(1)}+\sum_{1}^{(2)} .
\end{aligned}
$$

We have

$$
\begin{aligned}
\sum_{1}^{(2)}= & \sum_{r=1}^{\infty} \sum_{l=2}^{\infty} \sum_{k \leq r, k<l} f(r, k, l) \\
= & \sum_{r=1}^{\infty} \sum_{2 \leq l \leq r} \sum_{k \leq r, k<l} f(r, k, l)+\sum_{r=1}^{\infty} \sum_{l>r} \sum_{k \leq r, k<l} f(r, k, l) \\
= & \sum_{r=1}^{\infty} \sum_{2 \leq l \leq r}\left(\sum_{k \leq l} f(r, k, l)-f(r, l, l)\right)+\sum_{l=2}^{\infty} \sum_{r<l} \sum_{k \leq r} f(r, k, l) \\
= & \sum_{r=1}^{\infty} \sum_{l \leq r}\left(\sum_{k<l} f(r, k, l)-f(r, l, l)\right) \\
& +\sum_{l=2}^{\infty}\left(\sum_{r \leq l} \sum_{k \leq r} f(r, k, l)-\sum_{i \leq l} f(l, k, l)\right) \\
= & \sum_{r=1}^{\infty} \sum_{l \leq r} \sum_{k \leq l} f(r, k, l)-\sum_{r=1}^{\infty} \sum_{l \leq r} f(r, l, l) \\
& +\sum_{l=1}^{\infty} \sum_{r \leq l} \sum_{k \leq r} f(r, k, l)-\sum_{l=1}^{\infty} \sum_{k \leq l} f(l, k, l) .
\end{aligned}
$$

Thus from (2.1) and (2.2), we obtain

$$
\begin{aligned}
\sum_{1}:= & \sum_{r=1}^{\infty} \sum_{k \leq r} \sum_{l=1}^{\infty} f(r, k, l) \\
= & \sum_{r=1}^{\infty} \sum_{k \leq r} \sum_{l \leq k} f(r, k, l)+\sum_{r=1}^{\infty} \sum_{l \leq r} \sum_{k \leq l} f(r, k, l) \\
& -\sum_{r=1}^{\infty} \sum_{l \leq r} f(r, l, l)+\sum_{l=1}^{\infty} \sum_{r \leq l} \sum_{k \leq r} f(r, k, l) \\
& -\sum_{l=1}^{\infty} \sum_{k \leq l} f(l, k, l) \\
= & \sum_{r=1}^{\infty} \sum_{k \leq r} \sum_{l \leq k}\{f(r, k, l)+f(r, l, k)+f(k, l, r)\} \\
& -\sum_{r=1}^{\infty} \sum_{k \leq r}\{f(r, k, k)+f(r, k, r)\} .
\end{aligned}
$$


Now we consider $\Sigma_{2}$. We also have

$$
\begin{aligned}
\sum_{2} & =\sum_{r=1}^{\infty} \sum_{k>r} \sum_{l=1 \infty} f(r, k, l)=\sum_{k=2}^{\infty} \sum_{r<k} \sum_{l=1}^{\infty} f(r, k, l) \\
& =\sum_{k=2}^{\infty}\left(\sum_{r \leq k} \sum_{l=1}^{\infty} f(r, k, l)-\sum_{l=1}^{\infty} f(k, k, l)\right) \\
& =\sum_{k=1}^{\infty} \sum_{r \leq k} \sum_{l=1}^{\infty} f(r, k, l)-\sum_{k=1}^{\infty} \sum_{l=1}^{\infty} f(k, k, l) .
\end{aligned}
$$

We observe that the first sum on the right of above is similar to that considered in $\Sigma_{1}$. Hence by (2.3) and the above, we obtain

$$
\begin{aligned}
\sum_{2}= & \sum_{r=1}^{\infty} \sum_{k \leq r} \sum_{l \leq k}\{(k, r, l)+f(l, r, k)+f(l, k, r)\} \\
& -\sum_{r=1}^{\infty} \sum_{k \leq r}\{f(k, r, k)+f(k, r, r)\}-\sum_{r=1}^{\infty} \sum_{k=1}^{\infty} f(r, r, k) .
\end{aligned}
$$

Finally, on combining (2.1), (2.3) and (2.4), we arrive at

$$
\begin{aligned}
\sum_{r, k, l=1}^{\infty} f(r, k, l) & \\
= & \sum_{r=1}^{\infty} \sum_{k \leq r} \sum_{l \leq k}\{f(r, k, l)+f(r, l, k)+f(k, l, r) \\
& \quad+f(k, r, l)+f(l, r, k)+f(l, k, r)\} \\
& -\sum_{r=1}^{\infty} \sum_{k \leq r}\{f(r, k, k)+f(r, k, r)+f(k, r, k)+f(k, r, r)\} \\
& -\sum_{r=1}^{\infty} \sum_{k=1}^{\infty} f(r, r, k) .
\end{aligned}
$$

This completes the proof of Theorem 2.1.

3. A transformation formula for double series. Let $\sum_{r, k=1}^{\infty} g(r, k)$ be an absolutely convergent double series with complex terms. Then the following transformation formula holds.

THEOREM 3.1. We have

$$
\sum_{r, k=1}^{\infty} g(r, k)=\sum_{r=1}^{\infty} \sum_{k \leq r} g(r, k)+\sum_{r=1}^{\infty} \sum_{k \leq r} g(k, r)-\sum_{r=1}^{\infty} g(r, r) .
$$


Proof. On taking

$$
f(r, k, l)= \begin{cases}g(r, k) & \text { if } l=1 \\ 0 & \text { otherwise }\end{cases}
$$

in Theorem 2.1, we obtain the assertion.

REMARK 3.1. A direct and simple proof of Theorem 3.1 could be given as follows:

$$
\begin{aligned}
\sum_{r, k=1}^{\infty} g(r, k) & =\sum_{r=1}^{\infty} \sum_{k \leq r} g(r, k)+\sum_{r=1}^{\infty} \sum_{k>r} g(r, k) \\
& =\sum_{r=1}^{\infty} \sum_{k \leq r} g(r, k)+\sum_{k=2} \sum_{r<k} g(r, k) \\
& =\sum_{r=1}^{\infty} \sum_{k \leq r} g(r, k)+\sum_{k=1}^{\infty}\left(\sum_{r \leq k} g(r, k)-g(k, k)\right) \\
& =\sum_{r=1}^{\infty} \sum_{k \leq r} g(r, k)+\sum_{r=1}^{\infty} \sum_{k \leq r} g(k, r)-\sum_{r=1}^{\infty} g(r, r) .
\end{aligned}
$$

The following special case of Theorem 2.1 will be particularly useful in the applications we had in mind.

THEOREM 3.2. Let $\sum_{r=1}^{\infty} f(r)$ and $\sum_{k=1}^{\infty} g(k)$ be two absolutely convergent series of complex terms. Then

$$
\begin{aligned}
\left(\sum_{r=1}^{\infty} f(r)\right)\left(\sum_{k=1}^{\infty} g(k)\right)= & \sum_{r=1}^{\infty} f(r) \sum_{k \leq r} g(k) \\
& +\sum_{r=1}^{\infty} g(r) \sum_{k \leq r} f(k)-\sum_{r=1}^{\infty} f(r) g(r) .
\end{aligned}
$$

In particular,

$$
2 \sum_{r=1}^{\infty} f(r) \sum_{k \leq r} f(k)=\left(\sum_{r=1}^{\infty} f(r)\right)^{2}+\sum_{r=1}^{\infty} f^{2}(r) .
$$

The following reciprocity theorem is an easy consequence of (3.1).

THEOREM 3.3. For $i \in\{0,1\}$, define the function $x_{i}$ by setting

$$
x_{i}(n)=(-1)^{i(n-1)} \text { for positive integral } n
$$


and write, for $s>1, f_{i}(s)=\sum_{n=1}^{\infty} x_{i}(n) n^{-s}$. For reals $a, b$ greater than 1 and $i, j \in\{0,1\}$, let

$$
P_{i, j}(a, b)=\sum_{r=1}^{\infty} \frac{x_{i}(r)}{r^{a}} \sum_{k \leq r} \frac{x_{j}(k)}{k^{b}} .
$$

Then

$$
P_{i, j}(a, b)+P_{j, i}(b, a)=f_{i}(a) f_{j}(b)+f_{l+j}(a+b) .
$$

REMARK 3.2. We note that for $i \in\{0,1\}$,

$$
f_{i}(s)=\left(1-i 2^{1-s}\right) \zeta(s),
$$

and, furthermore, Theorem 3.3 contains as special cases all the basic reciprocity relations, in a slightly different notation, on p. 47 of Nielsen [6]. As alluded to in the introduction, Nielsen made use of these relations to evaluate some infinite series and prove several recurrence relations and (1.1) and (1.2) are representatives of these. It may be of interest to note that M. S. Klamkin [3] posed the special case $a=3$ of (1.1) as a problem, and while submitting his solution [4] attributed (1.1) to G. T. Williams. Unaware of Nielsen's and William's work, W. E. Griggs, S. Chowla, A. J. Kempner and W. E. Mientka [2], proved (1.1) in the case $a=2$ and also that

$$
\sum_{n=1}^{\infty} \frac{1}{n}\left\{\frac{1}{(n+1)^{2}}+\frac{1}{(n+2)^{2}}+\cdots\right\}=\zeta(3) .
$$

But interestingly (1.1) in the case $a=2$ and (3.3) are in fact equivalent in view of the following: For any $a>1$ we have

$$
\sum_{r=1}^{\infty} \frac{1}{r^{a}} \sum_{k \leq r} \frac{1}{k}=\sum_{k=1}^{\infty} \frac{1}{r} \sum_{k>r} \frac{1}{k^{a}}+\zeta(a+1) .
$$

This follows from

$$
\begin{aligned}
\sum_{r=1}^{\infty} \frac{1}{r} \sum_{k>r} \frac{1}{k^{a}} & =\sum_{k=2}^{\infty} \frac{1}{k^{a}} \sum_{r<k} \frac{1}{r}=\sum_{k=2}^{\infty} \frac{1}{k^{a}}\left(\sum_{r \leq k} \frac{1}{k}-\frac{1}{k}\right) \\
& =\sum_{k=1}^{\infty} \frac{1}{k^{a}}\left(\sum_{r \leq k} \frac{1}{r}-\frac{1}{k}\right)=\sum_{k=1}^{\infty} \frac{1}{k^{a}} \sum_{r \leq k} \frac{1}{r}-\zeta(a+1) .
\end{aligned}
$$

Alternative proofs of (1.1) and (1.2) could be found, respectively, in R. Sita Ramachandra Rao and A. Siva Rama Sarma [7] and A. Siva Rama Sarma [8]. Their arguments are based on a certain generalization of a transformation formula due to J. Lehner and M. Newman [5]. 
4. Further applications of Theorem 2.1. Let $u, v, w \in\{0,1\}$ and $a$, $b, c$ be reals greater than 1 . We write

$$
P_{u, v, w}(a, b, c)=\sum_{r=1}^{\infty} \frac{x_{u}(r)}{r^{a}} \sum_{k \leq r} \frac{x_{v}(k)}{k^{b}} \sum_{l \leq k} \frac{x_{2}(l)}{l^{c}}
$$

where the function $x_{l}$ is as defined in $\S 3$. Then the following reciprocity relation holds.

THEOREM 4.1. We have

$$
\begin{aligned}
& P_{u, v, w}(a, b, c)+P_{u, w, v}(a, c, b)+ P_{v, w, u}(b, c, a)+P_{v, u, w}(b, a, c) \\
&+P_{w, u, v}(c, a)+P_{w, v, u}(c, b, a) \\
&= f_{u}(a) f_{v}(b) f_{w}(c)+f_{u}(a) f_{v+w}(b+c)+f_{v}(b) f_{w+u}(c+a) \\
&+f_{w}(c) f_{u+v}(a+b)+2 f_{u+v+w}(a+b+c)
\end{aligned}
$$

where $f_{i}(s)$ is as given in Theorem 3.3.

Proof. On taking $f(r, k, l)=x_{u}(r) r^{-a} x_{v}(k) k^{-b} x^{w}(l) l^{-c}$ in Theorem 2.1, we obtain

$$
\begin{aligned}
f_{u}(a) f_{v} & (b) f_{w}(c) \\
= & P_{u, v, w}(a, b, c)+P_{u, w, v}(a, c, b)+P_{v, w, u}(b, c, a) \\
& +P_{v, u, w}(b, a, c)+P_{w, u, v}(c, a, b)+P_{w, v, u}(c, b, a) \\
& -\left\{P_{u, v+w}(a, b+c)+P_{v+w, u}(b+c, a)\right. \\
& \left.\quad+P_{u w, v}(a+c, b)+P_{v, u+w}(b, a+c)\right\} \\
& -f_{u+v}(a+b) f_{w}(c) .
\end{aligned}
$$

But, by Theorem 3.3, we have

$$
\begin{aligned}
& P_{u, v+w}(a, b+c)+P_{v+w, u}(b+c, a) \\
& \quad=f_{u}(a) f_{v+w}(b+c)+f_{u+v+w}(a+b+c), \\
& P_{u+w, v}(a+c, b)+P_{v, u+w}(b, a+c) \\
& \quad=f_{u+w}(a+c) f_{v}(b)+f_{u+v+w}(a+b+c) .
\end{aligned}
$$

On substituting these on the right of (4.1), we arrive at the assertion of the Theorem.

REMARK 4.1. It may be noted that on choosing $u, v, w$ from among 0 and 1 , the above reciprocity theorem yields eight distinct reciprocity relations. For example, writing

$$
P(a, b, c)=P_{0,0,0}(a, b, c) \quad \text { and } \quad P_{1}(a, b, c)=P_{1,1,1}(a, b, c),
$$


we have

$$
\begin{gathered}
P(a, b, c)+P(a, c, b)+P(b, c, a) j+P(b, a, c) \\
+P(c, a, b)+P(c, b, a) \\
=\zeta(a) \zeta(b) \zeta(c)+\zeta(a) \zeta(b+c)+\zeta(b) \zeta(c+a) \\
+\zeta(c) \zeta(a+b)+2 \zeta(a+b+c),
\end{gathered}
$$

$$
\begin{aligned}
& P_{1}(a, b, c)+P_{1}(a, c, b)+P_{1}(b, c, a)+P_{1}(b, a, c) \\
& +P_{1}(c, a, b)+P_{1}(c, b, a) \\
& =\left(1-2^{1-a}\right)\left(1-2^{1-b}\right)\left(1-2^{1-c}\right) \zeta(a) \zeta(b) \zeta(c) \\
& \quad+\left(1-2^{1-a}\right) \zeta(a) \zeta(b+c)+\left(1-2^{1-b}\right) \zeta(b) \zeta(c+a) \\
& \quad+\left(1-2^{1-c}\right) \zeta(c) \zeta(a+b)+2\left(1-2^{1-(a+b+c)}\right) \zeta(a+b+c) .
\end{aligned}
$$

Specializing (4.2) and (4.3) with $a=b=c$, we obtain

$$
\begin{aligned}
P(a, a, a): & =\sum_{r=1}^{\infty} r^{-a} \sum_{k<r} k^{-a} \sum_{l<k} l^{-a} \\
& =\frac{1}{6}\left\{\zeta^{3}(a)+3 \zeta(a) \zeta(2 a)+2 \zeta(3 a)\right\} \\
P_{1}(a, a, a):= & \sum_{r=1}^{\infty}(-1)^{r-1} r^{-a} \sum_{k \leq r}(-1)^{k-1} k^{-a} \sum_{l \leq k}(-1) l^{-1} l^{-a} \\
= & \frac{1}{6}\left\{\left(1-2^{1-a}\right)^{3} \zeta^{3}(a)+3\left(1-2^{1-a}\right) \zeta(a) \zeta(2 a)\right. \\
& \left.+2\left(1-2^{1-3 a}\right) \zeta(3 a)\right\} .
\end{aligned}
$$

Since it is well known that for positive integral $n, \zeta(2 n)$ is a rational multiple of $\pi^{2 n}$ (cf. [1], \$12.12), from (4.4) and (4.5), we conclude that if $a$ is an even integer $\geq 2$, then each of $P(a, a, a)$ and $P_{1}(a, a, a)$ is a rational multiple of $\pi^{3 a}$. Further, since $\zeta(2)=\pi^{2} / 6, \zeta(4)=\pi^{4} / 90$ and $\zeta(6)=$ $\pi^{6} / 945$ (cf. [1], §12.12), we have, in particular,

$$
\begin{gathered}
\sum_{r=1}^{\infty} r^{-2} \sum_{k \leq r} k^{-2} \sum_{l \leq k} l^{-2}=\frac{31}{15,120} \pi^{6}, \\
\sum_{r=1}^{\infty}(-1)^{r-1} r^{-2} \sum_{k \leq r}(-1)^{k-1} \sum_{l \leq k}(-1)^{l-1} l^{-2}=\frac{109}{120,960} \pi^{6} .
\end{gathered}
$$

\section{REFERENCES}

[1] T. M. Apostol, Introduction to Analytic Number Theory, Springer-Verlag, New YorkHeidelberg-Berlin, 1976.

[2] W. E. Briggs, S. Chowla, A. J. Kempner and W. E. Mientka, On some infinite series, Scripta Math., 21 (1955), 28-30. 
[3] M. S. Klamkin, Advance problem 4564, Amer. Math. Monthly, 60 (1953), 716.

[4] Solution of the problem, 4564, Amer. Math. Monthly, 62 (1955), 129-130.

[5] J. Lehner and M. Newman, Sums involving Farey fractions, Acta Arith., 15 (1968/69), 181-187.

[6] N. Nielsen, Handbuch der theorie der Gammafunktion, Chelsea Publishing Company, 1965 (reprinted).

[7] R. Sita Ramachandra Rao and A. Siva Rama Sarma, Some identities involving the Riemann zeta function, Indian J. Pure and Appl. Math., 10 (1979), 602-607.

[8] A. Siva Rama Sarma, Some problems in the theory of Farey series and the Euler totient functions, Doctoral dissertation, Andhra University, 1980.

[9] G. T. Williams, A new method of evaluating $\zeta(2 n)$, Amer. Math. Monthly, 60 (1953), 19-25.

Received April 22, 1981. The first author is presently at the University of Alberta, Edmonton, on leave from Andhra University. Research by the second author is supported in part by a Canadian National Research Council Grant.

ANDHRA UNIVERSITY

WALTAIR, INDIA

AND

UNIVERSITY OF ALBERTA

EDMONTON, Alberta

CANADA 



\section{PACIFIC JOURNAL OF MATHEMATICS \\ EDITORS}

Donald BaBBITT (Managing Editor)

University of California

Los Angeles, CA 90024

Hugo RossI

University of Utah

Salt Lake City, UT 84112

C. C. Moore and Arthur Ogus

University of California

Berkeley, CA 94720
J. DugundiI

Department of Mathematics

University of Southern California

Los Angeles, CA 90089-1113

R. FINN and H. SAMELSON

Stanford University

Stanford, CA 94305

\section{ASSOCIATE EDITORS}
R. ARENS
E. F. BECKENBACH
B. H. NeUMANN
F. WOLF
K. YoshidA (1906-1982)

\section{SUPPORTING INSTITUTIONS}

\author{
UNIVERSITY OF ARIZONA \\ UNIVERSITY OF BRITISH COLUMBIA \\ CALIFORNIA INSTITUTE OF TECHNOLOGY \\ UNIVERSITY OF CALIFORNIA \\ MONTANA STATE UNIVERSITY \\ UNIVERSITY OF NEVADA, RENO \\ NEW MEXICO STATE UNIVERSITY \\ OREGON STATE UNIVERSITY
}

\author{
UNIVERSITY OF OREGON \\ UNIVERSITY OF SOUTHERN CALIFORNIA \\ STANFORD UNIVERSITY \\ UNIVERSITY OF HAWAII \\ UNIVERSITY OF TOKYO \\ UNIVERSITY OF UTAH \\ WASHINGTON STATE UNIVERSITY \\ UNIVERSITY OF WASHINGTON
}

The Supporting Institutions listed above contribute to the cost of publication of this Journal, but they are not owners or publishers and have no responsibility for its content or policies.

Mathematical papers intended for publication in the Pacific Journal of Mathematics should be in typed form or offset-reproduced (not dittoed), double spaced with large margins. Please do not use built up fractions in the text of the manuscript. However, you may use them in the displayed equations. Underline Greek letters in red, German in green, and script in blue. The first paragraph must be capable of being used separately as a synopsis of the entire paper. In particular it should contain no bibliographic references. Please propose a heading for the odd numbered pages of less than 35 characters. Manuscripts, in triplicate, may be sent to any one of the editors. Please classify according to the scheme of Math. Reviews, Index to Vol. 39. Supply name and address of author to whom proofs should be sent. All other communications should be addressed to the managing editor, or Elaine Barth, University of California, Los Angeles, California 90024.

There are page-charges associated with articles appearing in the Pacific Journal of Mathematics. These charges are expected to be paid by the author's University, Government Agency or Company. If the author or authors do not have access to such Institutional support these charges are waived. Single authors will receive 50 free reprints; joint authors will receive a total of 100 free reprints. Additional copies may be obtained at cost in multiples of 50 .

The Pacific Journal of Mathematics is issued monthly as of January 1966. Regular subscription rate: $\$ 132.00$ a year (6 Vol., 12 issues). Special rate: $\$ 66.00$ a year to individual members of supporting institutions.

Subscriptions, orders for numbers issued in the last three calendar years, and changes of address should be sent to Pacific Journal of Mathematics, P.O. Box 969, Carmel Valley, CA 93924, U.S.A. Old back numbers obtainable from Kraus Periodicals Co., Route 100, Millwood, NY 10546.

The Pacific Journal of Mathematics ISSN 0030-8730 is published monthly by the Pacific Journal of Mathematics at P.O. Box 969, Carmel Valley, CA 93924. Application to mail at Second-class postage rates is pending at Carmel Valley, California, and additional mailing offices. Postmaster: Send address changes to Pacific Journal of Mathematics, P. O. Box 969, Carmel Valley, CA 93924.

PUBLISHED BY PACIFIC JOURNAL OF MATHEMATICS, A NON-PROFIT CORPORATION

Copyright $\odot 1984$ by Pacific Journal of Mathematics 


\section{Pacific Journal of Mathematics}

\section{Vol. 113, No. $2 \quad$ April, 1984}

Alan Adolphson, On the Dwork trace formula ...................257

Amos Altshuler and Leon Steinberg, Enumeration of the quasisimplicial

3 -spheres and 4-polytopes with eight vertices .................. 269

Kenneth R. Goodearl, Cancellation of low-rank vector bundles .......... 289

Gary Fred Gruenhage, Ernest A. Michael and Yoshio Tanaka, Spaces

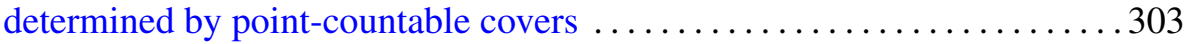

Charles Lemuel Hagopian, Atriodic homogeneous continua .......... 333

David Harbater, Ordinary and supersingular covers in characteristic $p$. . . 349

Domingo Antonio Herrero, Continuity of spectral functions and the lakes

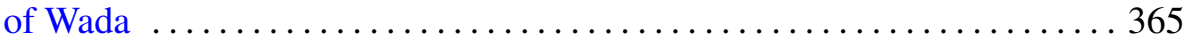

Donald William Kahn, Differentiable approximations to homotopy resolutions and framed cobordism ....................... 373

K. McGovern, On the lifting theory of finite groups of Lie type $\ldots \ldots \ldots . \ldots 383$

C. David (Carl) Minda, The modulus of a doubly connected region and the geodesic curvature-area method ............................. 395

Takuo Miwa, Complexes are spaces with a $\sigma$-almost locally finite base $\ldots . .407$

Ho Kuen Ng, Finitely presented dimension of commutative rings and modules

Roger David Nussbaum, A folk theorem in the spectral theory of

$C_{0}$-semigroups

J. S. Okon, Prime divisors, analytic spread and filtrations

Harold Raymond Parks, Regularity of solutions to elliptic isoperimetric problems

R. Sitaramachandra Rao and M. V. Subba Rao, Transformation formulae for multiple series

Daniel Ruberman, Imbedding punctured lens spaces and connected sums

Uri Srebro, Deficiencies of immersions 